\title{
Influence of Temperature Distribution on Circular Saw Blade Natural Frequencies during Cutting
}

\author{
Miran Merhar*
}

When cutting wood, heat is generated in the cutting zone and in the gullet due to the friction between the teeth of the blade and the material that is being cut. Since the wood is hydrophilic, the saw blade cannot be cooled with liquids, as is usual when cutting metals. The only way to remove the heat from the source is by conductivity to the centre of the saw blade and then by convection into the air. This research presents an analytical model to calculate the natural frequencies of circular saw blades exposed to different temperature distributions. The model confirmed experimental findings of many authors, i.e. the heating of the saw blade cutting edge reduces its natural frequencies, the rate of the reduction depending on the temperature difference between the cutting edge and the rest of the blade and on the shape of the temperature distribution. In contrast, heating the centre of the saw blade increases its natural frequencies, the rate of increase depending on the temperature difference and the shape of the temperature distribution. With the presented model, the most favourable temperature distribution can be calculated from the point of view of the critical saw blade speed, which can be achieved by heating or cooling the centre of the saw blade.

Keywords: Heating; Cooling; Temperature distribution; Vibration; Critical speed; Wood; Circular saw; Analytical model; Deformation; Stresses

Contact information: University of Ljubljana, Biotechnical Faculty, Department of Wood Science and Technology, Jamnikarjeva 101, SI-1000 Ljubljana, Slovenia;

*Corresponding author: miran.merhar@bf.uni-lj.si

\section{NOMENCLATURE}

$A_{1 \mathrm{mn}}, A_{2 \mathrm{mn}}, A_{3 \mathrm{mn}}, A_{4 \mathrm{mn},} \lambda_{\mathrm{mn}}$ Constants of mode shape function

$a \quad$ The clamping radius of the disc

$b \quad$ The outer radius of the disc

$c \quad$ Radius to which the saw blade is heated

E Young's modulus

$H$ Heaviside step function

$h \quad$ The thickness of the disk

$I_{n} \quad$ Modified Bessel functions of the first kind of order $n$

$J_{\mathrm{n}} \quad$ Bessel functions of the first kind of order $n$

$K \quad$ The kinetic energy of the vibrating disc

$K_{\mathrm{n}} \quad$ Modified Bessel functions of the second kind of order $n$

$k_{1}, k_{2}, k_{3}, k_{4}, k_{5}$ Experimentally determined constants

$M_{\mathrm{r}} \quad$ The effective transverse moment

$m \quad$ Nodal circle

$n \quad$ Nodal diameter

$r \quad$ Radius

$T_{\text {edge }} \quad$ Maximum temperature in the temperature distribution at the edge

$T_{\text {clamp }}$ Maximum temperature in temperature distribution in the centre of the disc 


$\begin{array}{ll}t & \text { Time } \\ U_{1} & \text { Strain energy of bending and twisting of the plate } \\ U_{2} & \text { Deformation energy from in-plane stresses } \\ u & \text { Radial displacement } \\ V_{\mathrm{r}} & \text { The effective transverse force } \\ w & \text { The shape of a vibrating circular plate } \\ Y_{\mathrm{n}} & \text { Bessel functions of the second kind of order } n \\ z & \text { Transverse displacement } \\ \gamma & \text { Experimentally determined exponent } \\ \theta & \text { Angular position } \\ \mu & \text { Poisson's ratio } \\ v & \text { Natural frequency } \\ \rho & \text { Material density } \\ \sigma_{\mathrm{r}} & \text { Radial stress } \\ \sigma_{\mathrm{t}} & \text { Tangential stress } \\ \tau & \text { Total temperature distribution } \\ \tau_{\text {edge }} & \text { Temperature distribution at the edge of the disc } \\ \tau_{\text {clamp }} & \text { Temperature distribution in the centre of the disc } \\ \Omega & \text { Saw blade rotation frequency } \\ \omega & \text { Natural frequency }\end{array}$

\section{INTRODUCTION}

In the process of wood cutting, the circular saw blade is a common tool and as such has been the subject of numerous experiments. The first experiments analysed the dynamic behaviour of circular saw blades (Mote and Szymani 1977; Leu and Mote 1984; Holoyen 1987; Parker and Mote 1989; Hutton 1991). Later some authors analysed more specifically the influence of rolling and laser tensioning on the stability of circular saw blades (Wasielewski et al. 2012; Zhang et al. 2014; Li et al. 2016; Merhar et al. 2017; Li and Zhang 2019a,b,c), while others focused on the development of new geometries and modifications of circular saw blades and machines (Bučar and Merhar 2008; Wasielewski et al. 2012; Droba et al. 2015; Kaczmarek et al. 2016a; Merhar and Bučar 2017; Krilek et al. 2020; Orlowski et al. 2020). In addition, new methods for the verification of dynamic properties of circular saw blades have emerged in recent years (Orlowski et al. 2007; Veselý et al. 2012; Svoreň et al. 2015; Kaczmarek et al. 2016b; Skoblar et al. 2016; Sandak and Orlowski 2018).

During wood cutting, heat is generated on the periphery of the blade as a result of friction between the teeth of the blade and the material that is being cut. Because wood is a good thermal insulator, all the resulting heat must be removed from the cut-off area through chips or through the tool - in this case, a circular saw blade. Because the cutting speeds are usually up to $100 \mathrm{~m} / \mathrm{s}$, the saw blade can rotate at a high rotational speed. For a saw blade with $300 \mathrm{~mm}$ in diameter the rotational speed could be $6000 \mathrm{rpm}$. Due to the high rotational speed, the heat source that is located in the cutting zone and in the gullet, can be regarded as axially symmetric, located on the entire periphery of the blade. The resulting heat is then transferred by conductivity towards the centre of the blade, and then by convection to the air.

The resulting temperatures can be high, which has negative consequences on the dynamics of the circular saw blade. The situation is even more unfavourable because the 
blade cannot be cooled down with coolant fluids, as is usually the case when cutting metals or other materials insensitive to liquids, because wood is strongly hydrophilic and absorbs water and other liquids. Thus, blade cooling by air is the most common way to remove heat from the blade.

The saw blade is thin in comparison to its diameter, where the thickness to diameter ratio is usually around 1 to 140 . In terms of dynamic behaviour, it has two forms of instability. The first is the so-called buckling, where the edge of the blade is heated up to the temperature when the blade buckles; and the second, which is more important, is the so-called saw blade critical speed, which is the saw blade speed at which the velocity of the backward traveling wave from the viewpoint of the stationary observer in space equals zero, which can also be called the standing wave (Stakhiev 2003). Because the saw blade can vibrate with many modes, where each has its own forward and backward traveling wave, each mode has its critical speed at which the backward travelling wave is stationary (Parker and Mote 1989). In this case, the saw blade can be in resonance with even a stationary force, which can be a touch of the workpiece with a blade. In practice, the lowest critical speed is where a vibrational mode establishes a standing wave. This is a vibrational mode with 0 nodal circle and 2 or 3 nodal diameters (Hutton 1991; Merhar et al. 2017).

However, because the temperature on the periphery decreases natural frequencies (Strzelecki 1974; Schajer 1986; Nishio and Marui 1996; Svoreň et al. 2017; Svoren et al. 2019), the critical speed of the saw blade and thereby the maximum rotational speed of the blade are also reduced. In practice, this case is usually solved with radial slots made on the periphery of the saw blade (Fig. 1). This reduces the internal tangential stresses caused by temperature differences, but due to the slots themselves the lateral stiffness of the blade also decreases, thereby decreasing natural frequencies and consequently the critical speed (Merhar and Bučar 2017).
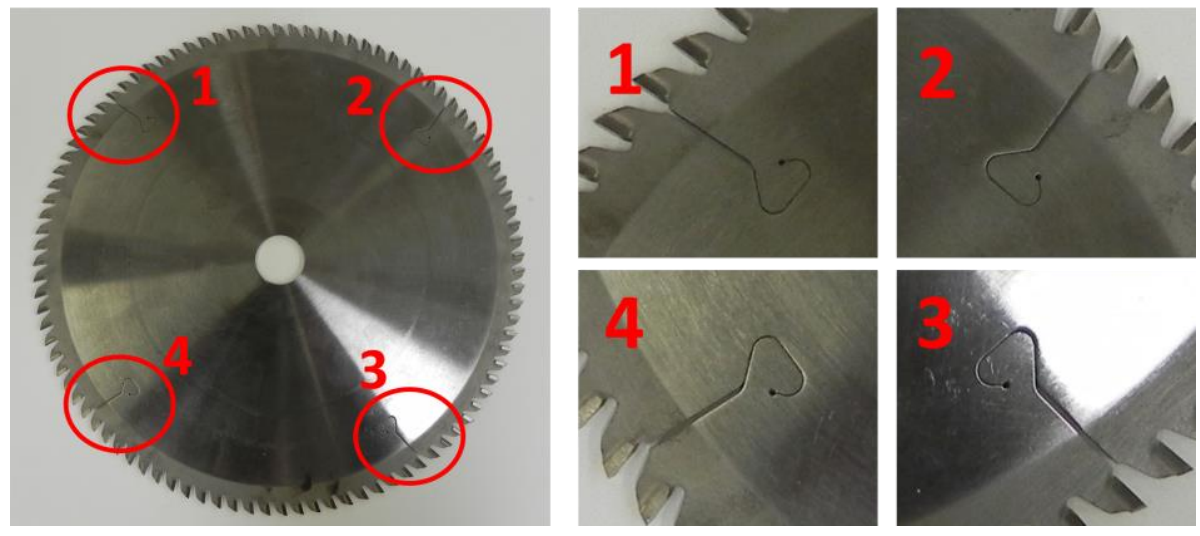

Fig. 1. Circular saw blade with radial slots

An alternative to the radial slots is cooling and heating of the centre of the blade when the natural frequencies increase, and hence the saw blade critical speed as well. Numerous authors have dealt with the described method (Mote 1966; Mote and Nieh 1973; Strzelecki 1974; Mote and Szymani 1977; Mote et al. 1981; Schajer 1986; Yu and Mote 1987), where they heated the outer edge as well as the centre of the blade to different temperatures, and measured the natural frequencies. However, by the author's knowledge the researchers did not determine the influence of the shape of the temperature distribution on the saw blade natural frequencies, and they did not evaluate the experimental findings with an analytical model describing the vibration of the blade under the influence of internal stresses. 
The aim of this work is therefore to apply the analytical model to confirm the experimental findings of various authors and, based on various temperature distributions experimentally determined by these authors, to investigate their influence on the natural frequencies of circular saw blades. The resulting model is used to find the worst-case scenario and to show the way to increase the natural frequencies by heating the central part of the saw blade and cooling the outer or middle part of the saw blade.

First, the equations for calculating the natural frequencies are derived on the basis of the strain and the kinetic energy of the vibrating blade. Then the method for determining the mode shape function is presented, which together with the stresses due to the temperature distribution in the blade and the centrifugal forces due to the rotation forms the equation for calculating the natural frequencies. Finally, the model is used to show different combinations of heating the central part of the blade and cooling the blade edge and their influence on the magnitude of the natural frequencies of the circular saw blade.

\section{THEORETICAL BACKGROUND}

\section{Natural Frequency Calculation}

The shape of a vibrating circular plate can be described with the deflection function $w$ (Warburton 1976),

$$
w(r, \theta, t)=z(r, \theta) e^{i \omega t}
$$

where $z(r, \theta)$ denotes the transverse displacement at any radius $r(\mathrm{~m})$ and angle $\theta(\mathrm{rad})$ as shown in Fig. 2, $t$ is time (s) and $\omega\left(\mathrm{rad} / \mathrm{s}^{-1}\right)$ is natural frequency. The kinetic energy of the vibrating disc is (Warburton 1976) calculated as:

$$
\begin{aligned}
& K=\frac{\rho h}{2} \int_{a}^{b} \int_{0}^{2 \pi}\left(\frac{\partial w}{\partial t}\right)^{2} r \mathrm{~d} \theta \mathrm{d} r=-\frac{\rho h \omega^{2}}{2} \int_{a}^{b} \int_{0}^{2 \pi} w^{2} r \mathrm{~d} \theta \mathrm{d} r=-\omega^{2} K_{1} \\
& K_{1}=\frac{\rho h}{2} \int_{a}^{b} \int_{0}^{2 \pi} w^{2} r \mathrm{~d} \theta \mathrm{d} r
\end{aligned}
$$

The strain energy of bending and twisting of the plate (Warburton 1976) is calculated as,

$U_{1}=\frac{D}{2} \int_{0}^{2 \pi} \int_{a}^{b}\left\{\left(\frac{\partial^{2} w}{\partial r^{2}}+\frac{1}{r} \frac{\partial w}{\partial r}+\frac{1}{r^{2}} \frac{\partial^{2} w}{\partial \theta^{2}}\right)^{2}-2(1-\mu)\left[\frac{\partial^{2} w}{\partial r^{2}}\left(\frac{1}{r} \frac{\partial w}{\partial r}+\frac{1}{r^{2}} \frac{\partial^{2} w}{\partial \theta^{2}}\right)-\left(\frac{1}{r} \frac{\partial^{2} w}{\partial r \partial \theta}-\frac{1}{r^{2}} \frac{\partial w}{\partial \theta}\right)^{2}\right]\right\} r \mathrm{~d} r \mathrm{~d} \theta$

and the deformation energy from in-plane stresses (Warburton 1976; Mote and Szymani 1977; Parker and Mote 1989) is calculated as Eq. 4,

$$
U_{2}=\frac{h}{2} \int_{0}^{2 \pi} \int_{a}^{b}\left\{\sigma_{\mathrm{r}}\left(\frac{\partial w}{\partial r}\right)^{2}+\sigma_{\theta}\left(\frac{1}{r} \frac{\partial w}{\partial \theta}\right)^{2}\right\} r \mathrm{~d} r \mathrm{~d} \theta
$$

where $\rho$ is material density $\left(\mathrm{kg} / \mathrm{m}^{3}\right), h$ is the thickness of the disk $(\mathrm{m}), a$ is the clamping radius $(\mathrm{m}), b$ is the outer radius of the disc $(\mathrm{m}), E$ is Young's modulus $(\mathrm{Pa}), \mu$ is Poisson's ratio, $\sigma_{\mathrm{r}}$ and $\sigma_{\mathrm{t}}$ are the radial and tangential stress $(\mathrm{Pa})$ in the disk, respectively, and:

$$
D=\frac{E h^{3}}{12\left(1-\mu^{2}\right)}
$$

Considering that the sum of all the energies $(\mathrm{J})$ of either the rotating or non-rotating vibrating disc were zero, this can be written as,

$$
K+U_{1}+U_{2}=-\omega^{2} K_{1}+U_{1}+U_{2}=0
$$


then, using the Rayleigh-Ritz method (Warburton 1976), the natural frequencies $v(\mathrm{~Hz})$ of the vibrating disc subjected to internal stresses can be calculated as:

$$
v=\frac{1}{2 \pi} \omega=\frac{1}{2 \pi} \sqrt{\frac{U_{1}+U_{2}}{K_{1}}}
$$

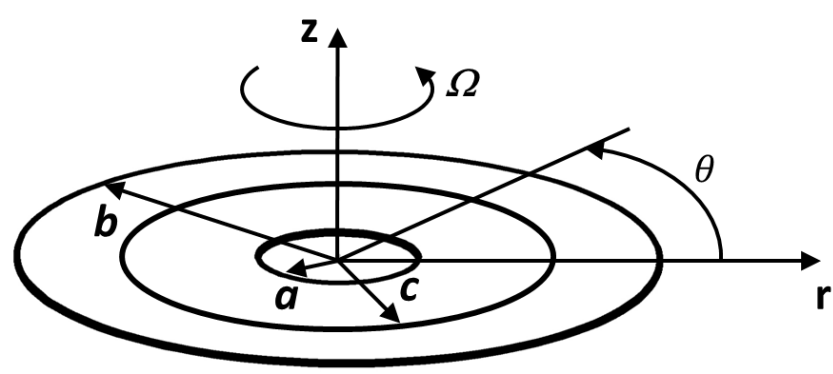

Fig. 2. Analytical model: $a$ - clamping radius, $b$ - saw blade radius, $c$ - radius to which the blade is heated, $\theta$ - angular position on the blade, and $\Omega$ - saw blade rotation frequency

To calculate the natural frequencies using Eqs. 2 through 7, the mode shapes' $w$ of the vibrating discs has to be known. When using approximate mode shapes, approximate natural frequencies are obtained, and when using exact mode shapes, exact natural frequencies of the vibrating disc can be calculated.

\section{Mode Shape Function Determination}

The function $w$, which is needed in Eqs. 2, 3, and 4, and describing the mode shape, can be derived from the solution of the differential equation describing the transversal vibration of a thin disk (Soedel 1993):

$$
\rho h \frac{\partial^{2} w}{\partial t^{2}}+D\left(\frac{\partial^{2}}{\partial r^{2}}+\frac{1}{r} \frac{\partial}{\partial r}+\frac{1}{r^{2}} \frac{\partial^{2}}{\partial \theta^{2}}\right)^{2} w=0
$$

Equation 8 can be solved by the method of separating the variables, where the solution is represented by Eq. 1. By inserting Eq. 1 into Eq. 8, the following equation is obtained:

$$
D\left(\frac{\partial^{2}}{\partial r^{2}}+\frac{1}{r} \frac{\partial}{\partial r}+\frac{1}{r^{2}} \frac{\partial^{2}}{\partial \theta^{2}}\right)^{2} z-\rho h \omega^{2} z=0
$$

The solution of Eq. 9 is,

$Z_{\mathrm{mn}}=\left[A_{1 m n} J_{n}\left(\lambda_{\mathrm{mn}} r\right)+A_{2 \mathrm{mn}} Y_{n}\left(\lambda_{\mathrm{mn}} r\right)+A_{3 \mathrm{mn}} I_{\mathrm{n}}\left(\lambda_{\mathrm{mn}} r\right)+A_{4 \mathrm{mn}} K_{\mathrm{n}}\left(\lambda_{\mathrm{mn}} r\right)\right] \cos (n \theta-\beta)$

where:

$$
\lambda_{\mathrm{mn}}^{4}=\frac{\rho h \omega_{\mathrm{mn}}^{2}}{D}
$$

$J_{\mathrm{n}}$ and $Y_{\mathrm{n}}$ are Bessel functions of the first and second kind of order $n$, respectively, $I_{n}$ and $K_{\mathrm{n}}$ are modified Bessel functions of first and second kind respectively, and $\beta$ is the phase angle, determined from the initial conditions in the case of a forced response. Because in this case only the mode shape is needed, $\beta$ can be 0 .

Equation 10 represents the mode shape function of the vibrating disc, which can vibrate with many natural frequencies and corresponding vibration mode shapes, where $m$ and $n$ represent the nodal circle and diameter, respectively. $A_{1 \mathrm{mn},} A_{2 \mathrm{mn},} A_{3 \mathrm{mn}}$, and $A_{4 \mathrm{mn}}$ as 
well as $\lambda_{\mathrm{mn}}$ are specific to each vibration mode shape and are determined from boundary conditions.

For a circular saw blade of radius $b$, which is clamped with the flange of radius $a$ (Fig. 2), the transversal displacements as well as the slope at $r=a$ are equal to zero:

$$
z(a)=0,\left.\frac{\partial z}{\partial r}\right|_{r=a}=0
$$

On the periphery at $r=b$ and any $\theta$, where the edge is free, the effective transverse force as well as moments are $V_{\mathrm{r}}=0$ and $M_{\mathrm{r}}=0$, respectively, where the moment and effective transverse force are (Warburton 1976) calculated as follows,

$$
M_{\mathrm{r}}=-D\left[\frac{\partial^{2} z}{\partial r^{2}}+\mu\left(\frac{1}{r} \frac{\partial z}{\partial r}+\frac{1}{r^{2}} \frac{\partial^{2} z}{\partial \theta^{2}}\right)\right] ; V_{\mathrm{r}}=Q_{\mathrm{r}}+\frac{1}{r} \frac{\partial M_{\mathrm{r} \theta}}{\partial \theta}
$$

where:

$$
Q_{\mathrm{r}}=-D \frac{\partial}{\partial r}\left(\frac{\partial^{2} z}{\partial r^{2}}+\frac{1}{r} \frac{\partial z}{\partial r}+\frac{1}{r^{2}} \frac{\partial^{2} z}{\partial \theta^{2}}\right) ; \quad M_{\mathrm{r} \theta}=-(1-\mu) D\left(\frac{1}{r} \frac{\partial^{2} z}{\partial r \partial \theta}-\frac{1}{r^{2}} \frac{\partial z}{\partial \theta}\right)
$$

Combining Eqs. 13 and 14, the boundary conditions at $r=b$ are,

$$
M_{\mathrm{r}}=-D\left[\frac{\partial^{2} z}{\partial r^{2}}+\mu\left(\frac{1}{r} \frac{\partial z}{\partial r}+\frac{1}{r^{2}} \frac{\partial^{2} z}{\partial \theta^{2}}\right)\right]=0
$$

and:

$$
V_{\mathrm{r}}=Q_{\mathrm{r}}+\frac{1}{r} \frac{\partial M_{\mathrm{r} \theta}}{\partial \theta}=-D\left[\frac{\partial}{\partial r}\left(\frac{\partial^{2} z}{\partial r^{2}}+\frac{1}{r} \frac{\partial z}{\partial r}+\frac{1}{r^{2}} \frac{\partial^{2} z}{\partial \theta^{2}}\right)+\frac{1-\mu}{r^{2}}\left(\frac{\partial^{3} z}{\partial r \partial \theta^{2}}-\frac{1}{r} \frac{\partial^{2} z}{\partial \theta^{2}}\right)\right]=0
$$

Considering the boundary conditions (Eqs. 15 and 16) and Eq. 10, the solution for each mode shape can be written in the matrix form,

$$
[Z]\left\{A_{\text {imn }}\right\}=\{0\}
$$

where:

$$
\left\{A_{\mathrm{imn}}\right\}=\left\{\begin{array}{l}
A_{1 \mathrm{mn}} \\
A_{2 \mathrm{mn}} \\
A_{3 \mathrm{mn}} \\
A_{4 \mathrm{mn}}
\end{array}\right\}
$$

For the solution to be nontrivial, the determinant of [Z] has to be zero,

$$
\operatorname{det}[Z]=0
$$

from which constants $A_{1 \mathrm{mn}}, A_{2 \mathrm{mn}}, A_{3 \mathrm{mn}}$, and $A_{4 \mathrm{mn}}$ as well as $\lambda_{\mathrm{mn}}$ can be calculated.

\section{In-plane Stresses Due to Induced Temperature Differences and Centrifugal Effects}

The equilibrium equation in the radial direction for the disc subjected to stresses due to axisymmetric temperature distribution and rotating at a rotation speed $\Omega$ is (Timoshenko 1956; Noda et al. 2003),

$$
\frac{\partial \sigma_{\mathrm{r}}}{\partial r}+\frac{\sigma_{\mathrm{r}}-\sigma_{\theta}}{r}+\rho \Omega^{2} r=0
$$

where $\sigma_{\mathrm{r}}$ and $\sigma_{\theta}$ are the radial stress and tangential stress $(\mathrm{Pa})$ in the disk, respectively,

$$
\sigma_{\mathrm{r}}=\frac{E}{1-\mu^{2}}\left[\frac{d u}{d r}+\mu \frac{u}{r}-(1+\mu) \alpha \tau\right]
$$




$$
\sigma_{\theta}=\frac{E}{1-\mu^{2}}\left[\mu \frac{d u}{d r}+\frac{u}{r}-(1+\mu) \alpha \tau\right]
$$

and $u$ and $\tau$ are the radial displacement and temperature distribution, respectively.

$$
u=(1+\mu) \frac{\alpha}{r} \int \tau r d r-\left(1-\mu^{2}\right) \frac{\rho \Omega^{2}}{E} \frac{r^{3}}{8}+C_{1} r+\frac{C_{2}}{r}
$$

Constants $C_{1}$ and $C_{2}$ can be determined from boundary conditions. Considering that the sawblade is clamped at radius $a$, and free at the edge $b$, the boundary conditions are:

$$
r=a ; u=0 \text { and } r=b ; \sigma_{\mathrm{r}}=0
$$

\section{Temperature Distribution}

According to numerous studies (Mote and Nieh 1973; Strzelecki 1974; Kollmann and Côte 1975; Mote and Szymani 1977; Mote et al. 1981), the distribution of temperature at the edge of the disc can be described by the function,

$$
\tau_{\text {edge }}=T_{\text {edge }}\left[\left(\frac{r}{b}\right)^{\gamma}-\kappa^{\gamma}\right]
$$

and the temperature distribution in the centre of the disc by Eq. 25 ,

$\tau_{\text {clamp }}=T_{\text {clamp }}\left[k_{1}\left(\frac{r-a}{c-a}\right)^{4}+k_{2}\left(\frac{r-a}{c-a}\right)^{3}+k_{3}\left(\frac{r-a}{c-a}\right)^{2}+k_{4} \frac{r-a}{c-a}+k_{5}\right][1-H(r-c)]$

where:

$$
\tau=\tau_{\text {clamp }}+\tau_{\text {edge }}
$$

$T_{\text {edge }}$ is the maximum temperature in the temperature distribution at the edge of the disc, $\kappa=a / b, \gamma$ is an experimentally determined exponent, being any integer or decimal value, $T_{\text {clamp }}$ is the maximum temperature $\left({ }^{\circ} \mathrm{C}\right)$ in temperature distribution in the centre of the disc, $c$ is the radius to which the blade is heated (Fig. 2), $H$ is Heaviside step function, and $k_{1}, k_{2}, k_{3}, k_{4}$, and $k_{5}$ are experimentally determined constants describing the temperature distribution.

\section{MATERIAL AND METHODS}

Due to frequent use in practice, and experiments performed (Mote and Nieh 1973; Strzelecki 1974; Mote and Szymani 1977; Mote et al. 1981) with circular saw blades of similar dimensions, a circular saw blade with a diameter of $300 \mathrm{~mm}$, clamping diameter of $75 \mathrm{~mm}$, and a thickness of $2.18 \mathrm{~mm}$ were taken for the calculation. The material density was $7850 \mathrm{~kg} / \mathrm{m}^{3}$, with a $200 \mathrm{GPa}$ Young's module, and Poisson's ratio 0.3 . The experimental temperature distributions were taken from the cited literature as well from Kollmann and Côte (1975).

The general procedure for calculating the natural frequencies was carried out according to the diagram in Fig. 3, whereby the shapes of the vibration modes for a specific saw blade must first be determined. Then the stresses and strain energy are calculated based on the temperature distribution at the edge and in the center of the saw blade, and the kinetic energy is calculated from the shapes of the vibration modes. The natural frequencies of the circular saw blade for a given vibration mode at specific temperature distribution are then calculated from both energies. 
However, since vibration modes with 2 or 3 nodal diameters usually have the lowest critical speeds, the natural frequencies for the specific temperature distribution were first calculated for vibration modes with node diameters from 0 to 6 and then the vibration mode with the lowest critical speed was determined. Since the vibrational mode with two nodal diameters had the lowest critical speed for the circular saw blade selected in the research, all further calculations for the vibration mode with two nodal diameters were performed.

All calculations have been performed by using the Wolfram Mathematica software (Wolfram, version 11.0, Oxfordshire, United Kingdom).

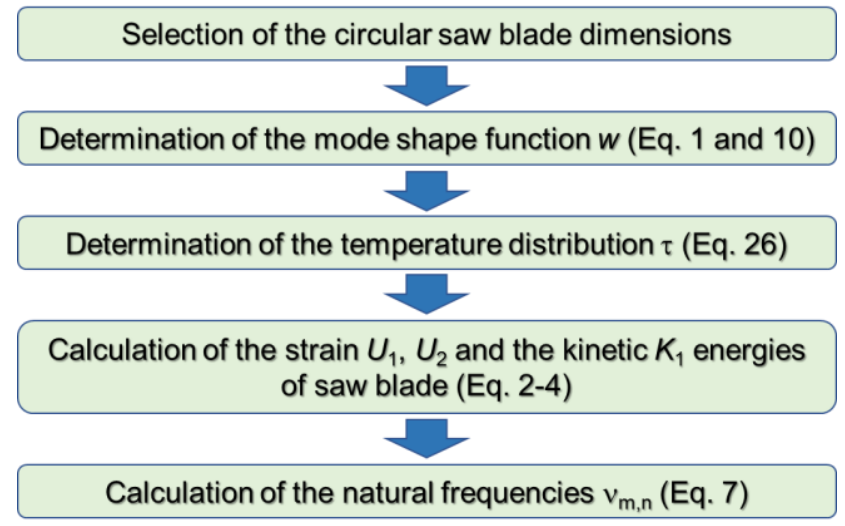

Fig. 3. Diagram for natural frequencies calculation

\section{RESULTS AND DISCUSSION}

Figure 4 shows the temperature distributions $\tau_{\text {edge }}$ (Eq. 24) for different values of the exponent $\gamma$ and $T_{\text {edge }}=40{ }^{\circ} \mathrm{C}$, where the distribution with $\gamma=10$ was taken from the literature (Kollmann and Côte 1975).

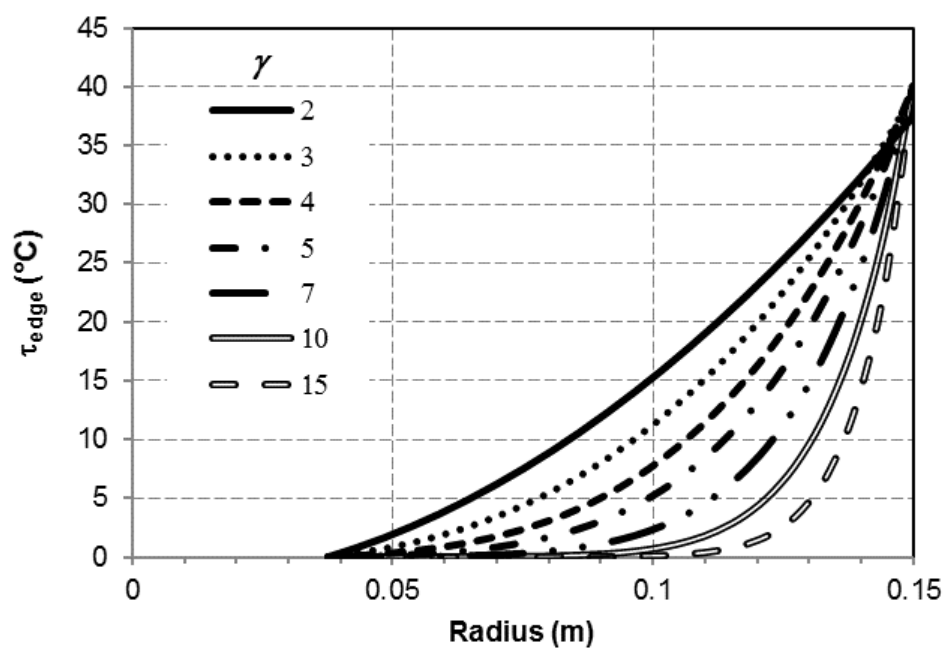

Fig. 4. Various edge temperature distributions $\tau_{\text {edge }}$ for $T_{\text {edge }}=40^{\circ} \mathrm{C}$ 


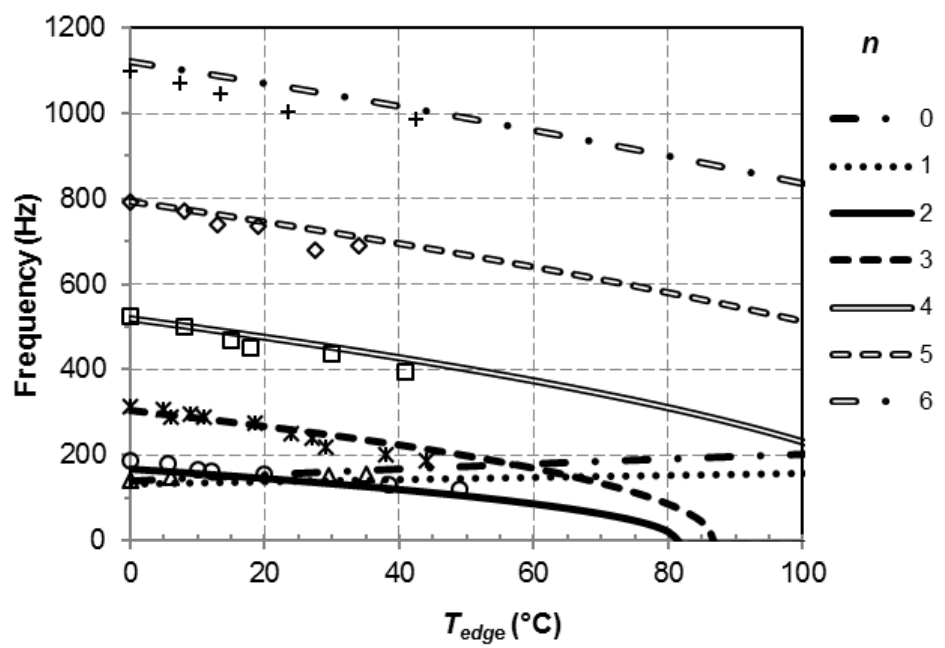

Fig. 5. Natural frequencies $v_{m, n}$ for mode shapes with 0 to 6 nodal diameter for various $T_{\text {edge }}$ and temperature distribution $\tau_{\text {edge }}$ with $\gamma=4$; Lines - theoretical values, points - experimental values

Figure 5 shows the calculated natural frequencies $v_{m, n}$ using Eq. 7 for different mode shapes with 0 nodal circle $m$ and nodal diameters $n$ from 0 to 6 at different values of $T_{\text {edge }}$ for temperature distribution with the value $\gamma=4$. The figure shows that the natural frequencies for the mode shapes with a nodal diameter greater than 2 decrease, while the frequencies for the nodal diameter 0 and 1 increase with the edge temperature. The calculated values correspond well to the literature (Kollmann and Côte 1975).

The critical speed of the saw blade is the most important from the stability point of view. When increasing the natural frequencies, the critical speed is also increased. Because for the circular saw blade analysed in the research the vibrational mode with two nodal diameters has the lowest critical speed (Fig. 5) (Merhar and Bučar 2017; Merhar et al. 2017), the rest of the work will be focused only on the frequencies of the vibrational mode with two nodal diameters.

Figure 6 shows the natural frequencies for the vibration mode with two nodal diameters.

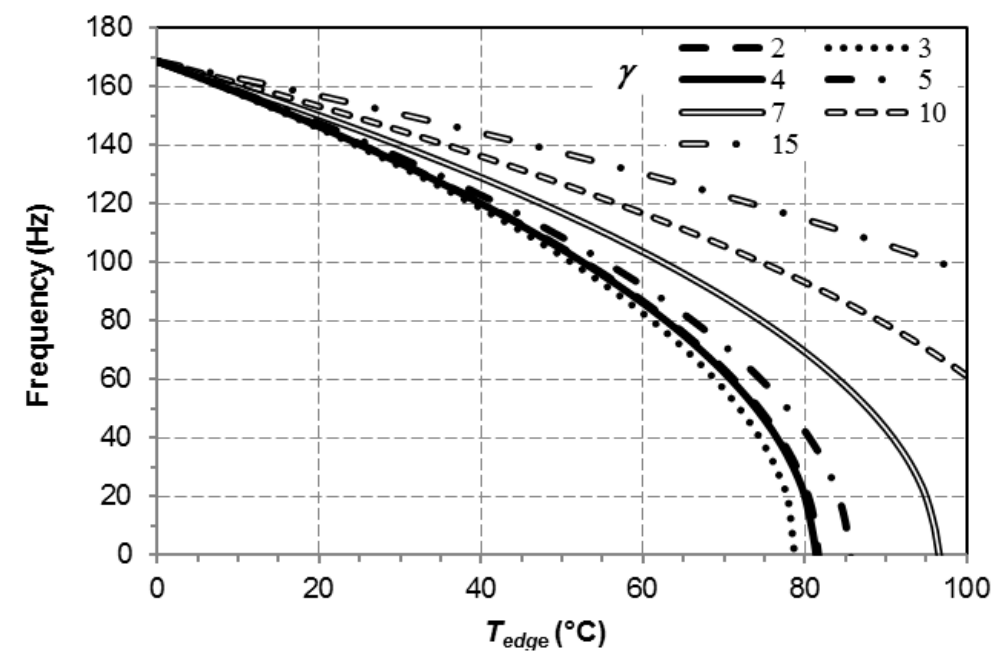

Fig. 6. Natural frequencies $v_{m, n}$ for mode shape with 2 nodal diameters at various temperature distributions and various $T_{\text {edge }}$ 
These are for different temperature distributions as shown in Fig. 4 and different $T_{\text {edge, }}$ where the frequencies decrease when the edge temperature increases, which was also found in Fig. 5. The rate of decrease depends on the shape of the temperature distribution, with the greatest drop occurring in temperature distribution when $\gamma$ equals 2,3 , and 4 . For the greatest value of $\gamma$, the rate of decrease is lower. It can be concluded from this analysis that it is reasonable to establish a temperature gradient with the highest value of $\gamma$. In practice, this means that it is reasonable to cool down the blade in the centre, or as close as possible to the edge, or to establish the most favourable conditions for cooling the blade.

In case of additionally heating the centre of the blade, natural frequencies can also be increased. Figure 7 shows the temperature distributions (Eq. 25) in the centre of the blade for different heating widths of the blade from clamping radius $a$ to radius $c$ at $T_{\text {clamp }}$ $=40^{\circ} \mathrm{C}$. The distribution with $c=0.08$ was taken from literature (Mote et al. 1981), from which also the coefficients for Eq. 25 were fitted and equal $k_{1}=7.89, k_{2}=-12.245, k_{3}=$ $0.689, k_{4}=3.67$, and $k_{5}=-0.0012$.

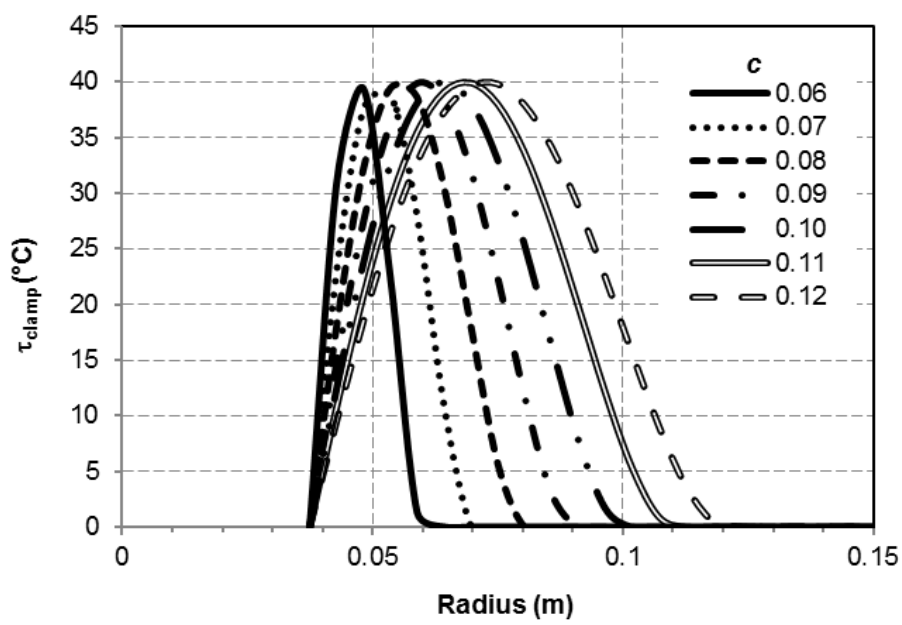

Fig. 7. Various disk centre temperature distributions $\tau_{\text {clamp }}$ at $T_{\text {clamp }}=40^{\circ} \mathrm{C}$ and various heating widths from clamping radius a to radius $c$

For the heating until radius $c=0.06 \mathrm{~m}$ and various $T_{\text {clamp }}$, Fig. 8 shows the calculated natural frequencies for different mode shapes with nodal diameter from 0 to 6 .

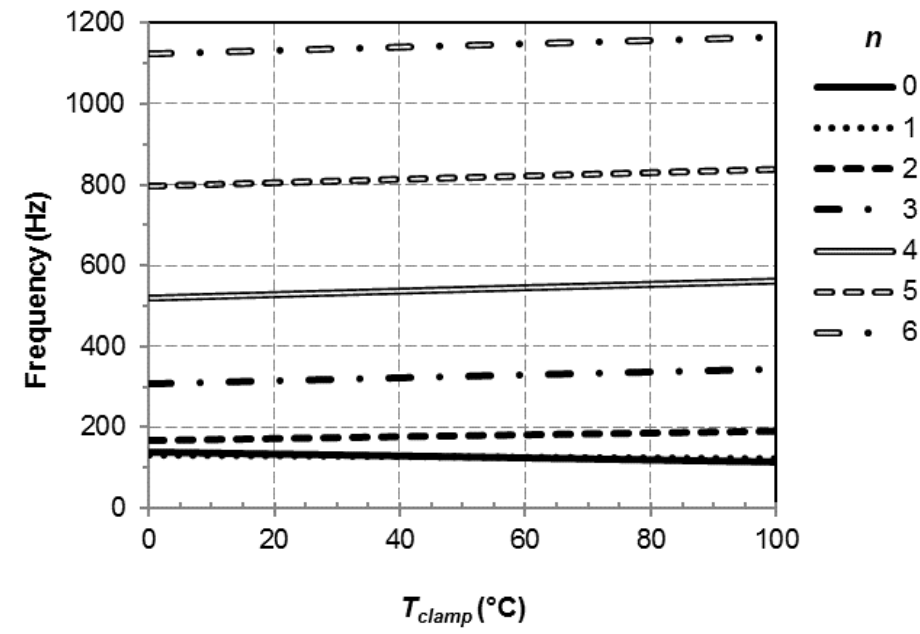

Fig. 8. Natural frequencies $v_{\mathrm{m}, \mathrm{n}}$ for mode shapes $n$ from 0 to 6 nodal diameters at various $T_{\text {clamp }}$ and heating radius $c=0.06 \mathrm{~m}$ 
It is clear from the figure that the natural frequencies for vibrational modes with

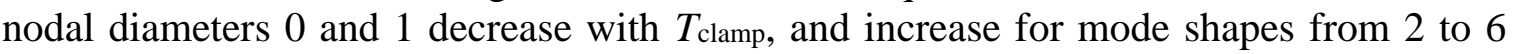
nodal diameters. These findings coincide with the literature (Mote and Nieh 1973; Strzelecki 1974; Mote and Szymani 1977; Mote et al. 1981). Considering that the mode shape with 2 nodal diameters has the lowest critical speed, Fig. 9 shows the natural frequencies for the mode shape with 2 nodal diameters at different $T_{\text {clamp }}$ and heating radius $c$. It can be seen from the figure that with the smallest radius $c$, the frequencies increase slowly with the temperature, while with the greater heating radius $c$ the natural frequencies increase faster and are higher at the same $T_{\text {clamp. }}$

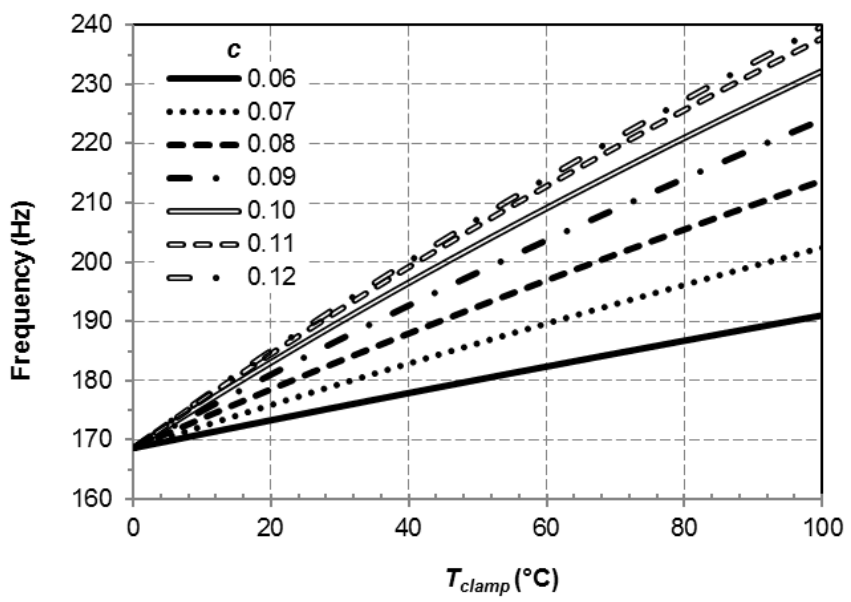

Fig. 9. Natural frequencies $v \mathrm{~m}, \mathrm{n}$ for mode shape with 2 nodal diameters at various $T_{\text {clamp }}$ and heating radius $C$

In practice, the high $T_{\text {clamp }}$ can be problematic from the safety point of view, because wood or dust that occurs during cutting is highly flammable or even explosive. For this reason, the combination of temperature distributions where the $T_{\text {clamp }}$ is $80{ }^{\circ} \mathrm{C}$ maximum will be examined, while one of the least favourable distributions with $\gamma=4$ will be taken

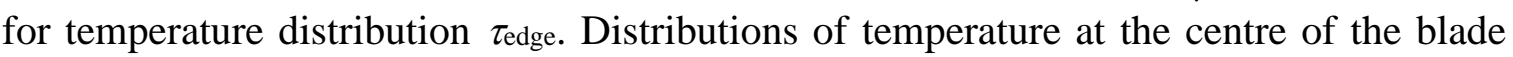
( $\left.\tau_{\text {clamp }}\right)$ with heating radius $c$ and temperature difference $T_{\text {clamp }}=40{ }^{\circ} \mathrm{C}$ together with the distributions of temperature at the edge of the blade $\tau_{\text {edge }}$ with $\gamma=4$ and $T_{\text {edge }}=40{ }^{\circ} \mathrm{C}$ are shown in Fig. 10.

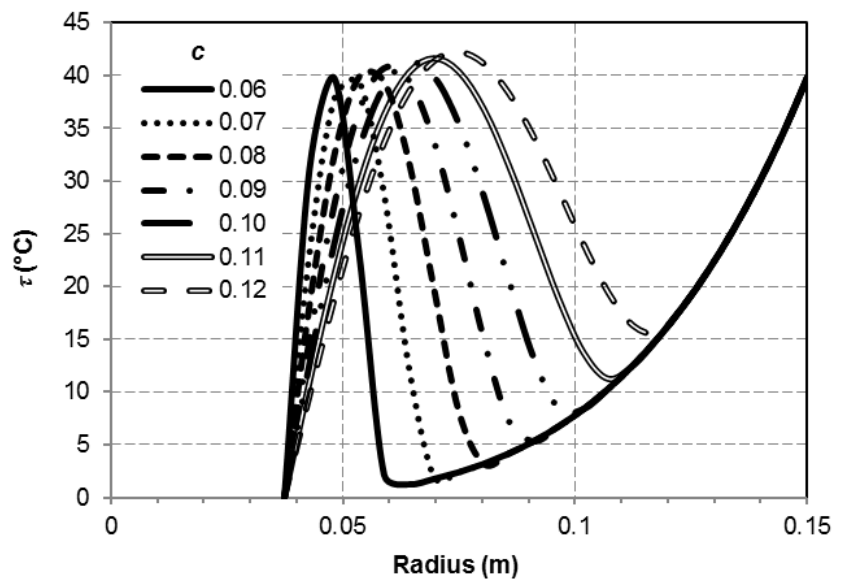

Fig. 10. Temperature distribution $\tau$ as a combination of the centre temperature $\tau_{\text {clamp }}$ at different radiuses $c$ and $T_{\text {clamp }}=40^{\circ} \mathrm{C}$ and edge temperature distribution $\tau_{\text {edge }}$ with $\gamma=4$ and $T_{\text {edge }}=40{ }^{\circ} \mathrm{C}$ 
The influence of the temperature distribution $\tau$ as a combination of $\tau_{e d g e}$ at different $T_{\text {edge }}$ and $\gamma=4$ together with $\tau_{\text {clamp }}$ and $T_{\text {clamp }}$ from 0 to $80{ }^{\circ} \mathrm{C}$ and heating radius $c=0.1 \mathrm{~m}$ on the natural frequencies for mode shape with 2 nodal diameters is shown in Fig. 11. The natural frequencies decrease with the increase of $T_{\text {edge, }}$ while with $T_{\text {clamp }}$, the frequencies increase. For example, the natural frequency for mode shape with 2 nodal diameters and without temperature differences decreased from $174 \mathrm{~Hz}$ to $109 \mathrm{~Hz}$ when the $T_{\text {edge }}$ temperature increased $54{ }^{\circ} \mathrm{C}$, and then further increased back to $174 \mathrm{~Hz}$ when the centre of the blade $T_{\text {clamp }}$ was heated to $80{ }^{\circ} \mathrm{C}$. However, it is important to emphasize that the intermediate zone should be cooled, otherwise the edge of the blade will be further heated.

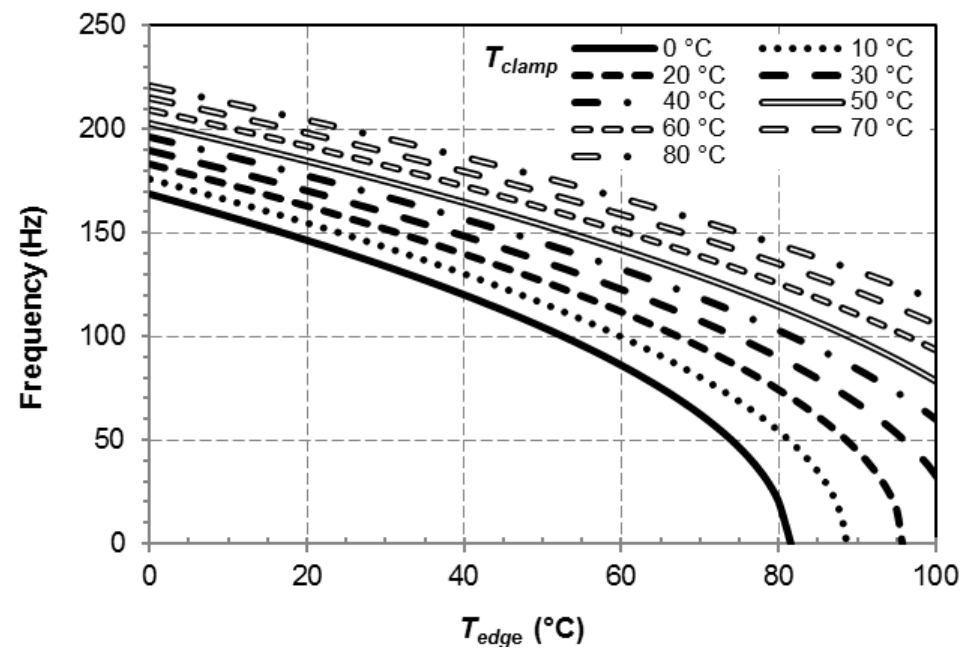

Fig. 11. Natural frequencies $v_{\mathrm{m}, \mathrm{n}}$ for mode shape with 2 nodal diameters, heating radius $c=0.1$ $\mathrm{m}$, for various $T_{\text {clamp }}$ and $T_{\text {edge }}$ for the edge temperature distribution with $\gamma=4$

Figure 12 shows the influence of the heating radius $c$ on the natural frequencies for the vibrational mode with 2 nodal diameters at different $T_{\text {edge }}$ and with $T_{\text {clamp }}=80{ }^{\circ} \mathrm{C}$. It is evident from the figure that the natural frequencies increased with the increase of the heating radius $c$. However, it is necessary to re-emphasize that the blade in the intermediate area must be cooled, which means that heating radius $c$ is limited.

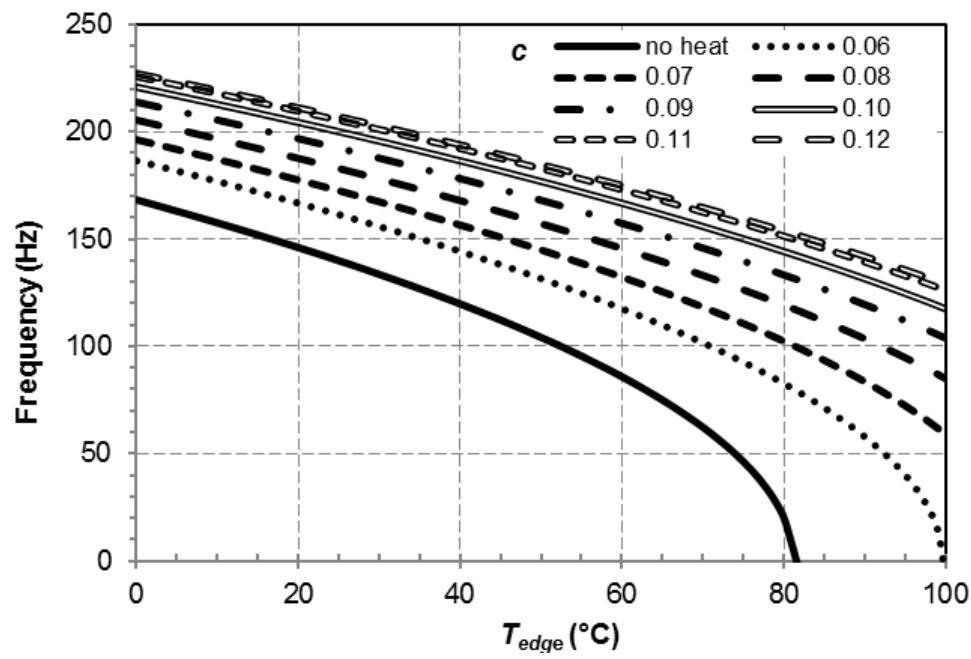

Fig. 12. Natural frequencies $v_{\mathrm{m}, \mathrm{n}}$ for mode shape with 2 nodal diameters, $T_{\text {clamp }}=80^{\circ} \mathrm{C}$, different heating radius $c$, and edge temperature $T_{\text {edge }}$ 


\section{CONCLUSIONS}

1. The model confirmed a number of sets of experimental data, which were published by numerous authors who studied the influence of the saw blade temperature on its natural frequencies, where higher temperatures on the periphery of the blade decrease the natural frequencies of the blade and thus the critical speed of the saw blade.

2. The model also showed the effect of the temperature distribution on the natural frequencies of circular saw blades, and determined the most problematic one from the critical speed point of view. It was found that optimal conditions should be provided to enable the most efficient cooling of saw blades, because in this way the fall of natural frequencies is lower than otherwise.

3. The model also confirmed the experimental findings that the natural frequencies of the blade can be increased by heating the centre of the blade, where both the heating area as well as the temperature affects the increase of the natural frequencies. Further, the model obtained can serve for better understanding of dynamic behaviour of the circular saw blades.

4. The model presented can be used in practice for the design of heating or cooling systems on existing circular sawing machines and for existing circular saw blades. In this way the critical speed of circular saw blades can be increased as well as the maximum rotational speed and as a consequence the capacity of the machines. The presented model can also be used in the development of new circular saw blades, especially for thinner blades, which are characterized by lower critical speeds.

5. Circular saw blades normally have the lowest critical speeds in vibration modes with two or three nodal diameters. In the analysed saw blade, the lowest critical speed had a two nodal diameter mode, but in case of a saw blade with different dimensions, the three nodal diameter mode could have the lowest critical speed instead of the mode with two nodal diameters. Therefore, for each circular saw blade, it must first be checked which vibration mode has the lowest critical speed.

\section{ACKNOWLEDGMENTS}

The author acknowledges the support of the Slovenian Research Agency within the framework of programs P2-0182.

\section{REFERENCES CITED}

Bučar, B., and Merhar, M. (2008). "Modelling of response of aerodynamic excited idling circular saw blade with geometrical imperfection," Wood Research 53(3), 111-120.

Droba, A., Javorek, L., Svoreň, J., and Paulíny, D. (2015). "New design of circular saw blade body and its influence on critical rotational speed," Drewno 58(194), 147-157. DOI: 10.12841/wood.1644-3985.081.12

Holoyen, S. (1987). "Vibrations and natural frequencies of angular slot circular saws," Holz als Roh- und Werkstoff 45(3), 101-104. DOI: 10.1007/BF02605981

Hutton, S. G. (1991). "The dynamics of circular saw blades," Holz als Roh- und Werkstoff 49(3), 105-110. DOI: 10.1007/BF02614349

Kaczmarek, A., Orłowski, K., and Javorek, L. (2016a). "The effect of circular saw blade 
clamping diameter on its resonant frequencies," Applied Mechanics and Materials 838, 18-28. DOI: 10.4028/www.scientific.net/AMM.838.18

Kaczmarek, A., Orlowski, K. A., and Javorek, L. (2016b). "A brief review and comparison of selected experimental methods for measuring natural frequencies of circular saw blades," Drewno 59(197), 231-239. DOI: 10.12841/wood.16443985.C09.11

Kollmann, F. F. P., and Côte, W. A. (1975). Principles of Wood Science and Technology. Solid Wood, Springer-Verlag, Berlin, Germany.

Krilek, J., Ťavodová, M., Kováč, J., and Tichý, B. (2020). "Impact of irregular tooth pitch of circular saw blades on power for wood cross-cutting," Drvna Industrija 71(1), 311. DOI: $10.5552 /$ drvind.2020.1824

Leu, M. C., and Mote, C. D. (1984). "Origin of idling noise in circular saws and its suppression," Wood Science and Technology 18(1), 33-49. DOI: 10.1007/BF00632129

Li, B., and Zhang, Z. (2019a). "Laser shock process as new tensioning method for circular saw blade," Wood Research 64(4), 705-718.

Li, B., and Zhang, Z. K. (2019b). "Analysis and optimization of the tensioning effect on a wood-cutting circular saw blade tensioned by multispot pressure," Forest Products Journal 69(1), 61-69. DOI: 10.13073/fpj-d-17-00063

Li, B., and Zhang, Z. K. (2019c). "Theoretical modeling and analysis for laser shock tensioning process of circular saw blade," Optics and Laser Technology 114, 181-189. DOI: 10.1016/j.optlastec.2019.01.047

Li, S., Wang, C., Zheng, L., Wang, Y., Xu, X., and Ding, F. (2016). "Dynamic stability of cemented carbide circular saw blades for woodcutting," Journal of Materials Processing Technology 238, 108-123. DOI: 10.1016/j.jmatprotec.2016.07.018

Merhar, M., and Bučar, D. G. (2017). "The influence of radial slots on dynamic stability of thermally stressed circular saw blade," Drvna Industrija 68(4), 341-349. DOI: 10.5552/drind.2017.1739

Merhar, M., Bučar, D. G., and Pepelnjak, T. (2017). "Dynamic behaviour analysis of a commercial roll-tensioned circular sawblade," BioResources 12(3), 5569-5582. DOI: 10.15376/biores.12.3.5569-5582

Mote, C. D., and Nieh, T. (1973). "On the foundation of circular saw stability theory," Wood and Science 5(2), 160-169.

Mote, C. D., and Szymani, R. (1977). "A review report on principal developments in thin circular saw vibration and control research: Part 1: Vibration of circular saws," Holz als Roh- und Werkstoff 35(5), 189-196. DOI: 10.1007/BF02610942

Mote, C. D. (1966). "Theory of thermal natural frequency variations in disks," International Journal of Mechanical Sciences 8(8), 547-557. DOI: 10.1016/00207403(66)90004-X

Mote, C. D., Schajer, G. S., and Holoyen, S. (1981). "Circular saw vibration control by induction of thermal membrane stresses," Journal of Engineering for Industry 103(1), 81-89. DOI: $10.1115 / 1.3184465$

Nishio, S., and Marui, E. (1996). "Effects of slots on the lateral vibration of a circular saw blade," International Journal of Machine Tools \& Manufacture 36(7), 771-787. DOI: 10.1016/0890-6955(95)00088-7

Noda, N., Hetnarski, R. B., and Tanigawa, Y. (2003). Thermal Stresses, Taylor \& Francis, New York, NY, USA.

Orlowski, K., Sandak, J., and Tanaka, C. (2007). "The critical rotational speed of circular saw: Simple measurement method and its practical implementations," Journal of Wood Science 53(5), 388-393. DOI: 10.1007/s 10086-006-0873-5 
Orlowski, K. A., Dudek, P., Chuchala, D., Blacharski, W., and Przybylinski, T. (2020). "The design development of the sliding table saw towards improving its dynamic properties," Applied Sciences-Basel 10(20). DOI: 10.3390/app10207386

Parker, R. G., and Mote, C. D. (1989). "Asymmetric tensioning of circular saws," Holz als Roh- und Werkstoff 47(4), 143-151. DOI: 10.1007/BF02614477

Sandak, J., and Orlowski, K. A. (2018). "Machine vision detection of the circular saw vibrations," Journal of Machine Engineering 18(3), 67-77. DOI: 10.5604/01.3001.0012.4617

Schajer, G. S. (1986). "Why are guided circular saws more stable than unguided saws?," Holz als Roh- und Werkstoff 44(12), 465-469. DOI: 10.1007/BF02608068

Skoblar, A., Andjelic, N., and Zigulic, R. (2016). "Determination of critical rotational speed of circular saws from natural frequencies of annular plate with analogous dimensions," International Journal for Quality Research 10(1), 177-192. DOI: 10.18421/IJQR10.01-09

Soedel, W. (1993). Vibrations of Shells and Plates, Marcel Dekker, New York, NY.

Stakhiev, Y. M. (2003). "Research on circular saw disc problems: Several of results," Holz als Roh - und Werkstoff 61(1), 13-22. DOI: 10.1007/s00107-002-0353-6

Strzelecki, A. (1974). "Erzwungene schwingungen und resonanzschwingungen von kreissageblattern fur den einschnitt von holz. 2. Ungleichmassige erwarmung des sageblattes [Forced and resonant vibrations of circular saw blades for cutting wood. 2. Unequal heating of the saw blade]," Holztechnologie 15, 205-211.

Svoreň, J., Javorek, L., Droba, A., and Paulíny, D. (2015). "Comparison of natural frequencies values of circular saw blade determined by different methods," Drvna Industrija 66(2), 123-126. DOI: 10.5552/drind.2015.1316

Svoreň, J., Javorek, L., Krajčovičová, M., Klobǔiaková, K., Kubovský, I., and Kminiak, R. (2017). "The effect of the circular saw blade body structure on the concentric distribution of the temperature along the radius during the wood cutting process," Wood Research 62(3), 427-436.

Svoren, J., Javorek, L., and Nascák, L. (2019). "Interchange of heat in saw disc body during cutting," International Journal of Engineering and Management Sciences 4(1), 488-494. DOI: 10.21791/IJEMS.2019.1.60.

Timoshenko, S. (1956). Strength of Materials. Part 2: Advanced Theory and Problems, Van Nostrand Company, New York, NY, USA.

Veselý, P., Kopecký, Z., Hejmal, Z., and Pokorný, P. (2012). "Diagnostics of circular sawblade vibration by displacement sensors," Drvna Industrija 63(2), 81-86. DOI: 10.5552/drind.2012.1130

Warburton, G. B. (1976). The Dynamical Behaviour of Structures, Pergamon Press, Oxford, UK.

Wasielewski, R., Orlowski, K. A., and Szyszkowski, S. (2012). "Economical wood sawing with circular saw blades of a new design," Drvna Industrija 63(1), 27-32. DOI: $10.5552 /$ drind.2012.1121

Yu, R. C., and Mote, C. D. (1987). "Vibration of circular saws containing slots," Holz als Roh- und Werkstoff 45(4), 155-160. DOI: 10.1007/BF02627571

Zhang, M. S., Zhang, Y., Ke, J. J., Li, X. W., and Cheng, L. B. (2014). "The influence of tangential roller pressure on the stability of circular saw blade," Applied Mechanics and Materials 614, 32-35. DOI: 10.4028/www.scientific.net/AMM.614.32

Article submitted: October 29, 2020; Peer review completed: December 6, 2020; Revised version received and accepted: December 14, 2020; Published: December 17, 2020.

DOI: 10.15376/biores.16.1.1076-1090 